\title{
Model of formation of professional activity safety culture of future occupational safety and health engineers
}

\author{
Valentyna Radkevych ${ }^{1}$, and Elviza Abiltarova ${ }^{1, *}$ \\ ${ }^{1}$ Institute of Vocational Education and Training of the National Academy of Pedagogical Sciences of \\ Ukraine Vito-Litovskiy Line 98 A, 03045 Kyiv, Ukraine
}

\begin{abstract}
The purpose of the article is to consider the model of the formation of the safety culture of professional activity in future occupational safety and health engineers. The urgency of the implementation of the stated research within the Concept of sustainable development has been substantiated. The study establishes the structure of the model represented by five blocks: prospective-target, theoreticalmethodological, content-technological, diagnostic-resultant. The prospective-target block defines the goals and objectives of the research; the theoretical-methodological block provides for a concept, methodological approaches, principles, factors, pedagogical conditions that contribute to the effective formation of the culture of safety of professional activity; content-technological is expressed by a complex of didactic units that include content components, forms, methods and technologies of teaching; the diagnostic-resultant block contains diagnostic tools for the formation of the safety culture of professional activity among future engineers on labor protection. The conclusion is made about the dynamism and balance of the components of the proposed model, aimed at the personal growth of future occupational safety and health engineers and the development of their creative potential, most significantly focused on the prevention of the risks and harm caused by occupational hazards.
\end{abstract}

\section{Introduction}

Within the concept of sustainable development, the system of vocational training of occupational safety and health engineers (OSH engineers) requires the formation and development of the culture of safety of professional activity (CSPA), which is an integral quality of a specialist's personality, expressed by a combination of professional knowledge, skills, professional and personal qualities in the prevention of accidents at work and occupational injuries and diseases, reducing the level of occupational risks; manifested by a motivational-value attitude towards personal safety and the safety of the entire team, the creation of safe and harmless working conditions.

\footnotetext{
*Corresponding author: elviza2008@gmail.com
} 
In the progress of the scientific search for the implementation of the research tasks, we established an urgent need to build and substantiate a model for the formation of the culture of safety of professional activity among future occupational safety and health engineers. The results of the analysis of scientific publications made it possible to determine that the issues of modeling in pedagogical research were considered by various scientists. The founders of the theory of modeling are V. Shtoff [1]. In domestic science, the ideas of the model approach in pedagogy were laid by V. Bespalko [2], V. Zagvyazinsky [3], V. Kraevsky [4], P. Luzan [5], V. Radkevych [6], V. Serikov [7], E. Khrykov [8]. One of the aspects of our research was the search for scientific publications related to the development of a model of the formation of the safety culture and the culture of life safety.

The results of the analysis of scientific and pedagogical literature allow us to state the diversity of researchers' views on the indicated problem. A. Dronov [9, p.56] proposed a model of the formation of the life safety culture of students, which enables the teacher to implement the entire process consistently from a lower level to a higher level.The pedagogical model of the formation of a safe and healthy lifestyle is considered by A. Shinkarenko [10] from the standpoint of the theoretical-methodological and organizationalpedagogical aspect. In the aspect of our research, the model of the culture of safety of professional activity by N. Usachev [11], which includes motivational-value, cognitive and activity components, attracts special attention. In the process of building a model of the formation of the corporate culture of safe work in small enterprises, M. Zubkov [12] identified the following basic elements: the cultural component of labor safety, personalitydetermined factors of the behavior of a particular employee and the structure of relations within corporate teams of enterprises, and according V. Tseiko [13, pp. 66-67] the content of the model of process of forming a life safety culture among high school students includes the following components: motivational-need, emotional-volitional, cognitive and operational-activity.

In the course of scientific research, we found that when using the modeling method in pedagogical research, scientists use various types of models. We are impressed by V. Moshkin's [14, p. 226] model of the process of educating schoolchildren on safety culture. The model of formation of safety culture in the educational environment proposed by $\mathrm{E}$. Trofimets [15] includes the following types: conceptual model of knowledge integration; didactic model of safety culture formation in the educational environment; model of visual modeling of cognitive activity. Considering that CSPA is associated with harmful impact of the production process on the environment, scientific achievements in the field of modeling by L. Gorina [16], I. Dolinina [17], A. Kazmina [18] are of particular relevance for our research.

Considerable interest and theoretical significance in the development of vocational education is aroused by the large groundwork of domestic scientists. S. Alekseeva [19] proposed a model of training future designers for the professional career development; R. Zozulya-Sluchik [20] developed a model for the formation of professional ethics of future social workers in universities; N. Kulalaeva [21] substantiated a model for the formation of safety culture of professional activity among future builders; A. Radkevich [22] updated the model of the pedagogical system for the development of legal culture of pedagogical workers of vocational education institutions.

The analysis of scientific and pedagogical literature showed that in the theory and methodology of vocational education, the problem of forming the safety culture of professional activity among future OSH engineers requires a deeper study based on the use of the modeling method. Taking into account the above, the purpose of the article is to substantiate the model of the formation of the safety culture of professional activity among future $\mathrm{OSH}$ engineers. 


\section{Research methodology and methods}

The methodological basis of the study was the application of the method of historical, logical and systemic analysis of existing practices and approaches to the study of the problem of safety culture from the aspects of pedagogical, psychological, philosophical and sociological sciences.

The construction of the model is based on the humanistic, personality-oriented and culturological paradigms that make up the concept of the work. In the process of scientific research, we use the following research methods: abstraction to highlight certain properties, features, constituent elements, and blocks in the model; analysis, synthesis, systematization and generalization of scientific publications; comparative analysis of various models presented in the scientific literature; theoretical modeling for building a model in order to determine the effectiveness of the process of forming the culture of safety of professional activity among future OSH engineers and the development of measures to optimize and improve it; thought experiment for predicting risks, identifying problem areas and clarifying the blocks and components of the projected model.

\section{Results and discussion}

The analysis of scientific and pedagogical literature, dissertation research works allowed us to determine the structure of the model for the formation of CSPA in future OSH engineers represented by five blocks: prospective-target, theoretical-methodological, contenttechnological, diagnostic-effective (Fig. 1). Let's consider in more detail each of the blocks presented. The initial conditions for the implementation of the created model are the requirements of state educational standards, as well as the social order of society for the professional training of OSH engineers for various sectors of the economy with a high level of CSPA and a readiness to use safe and health-saving technologies to preserve the life and health of the entire team in the labor process, capable of preventing occupational injuries based on safety principles.

The prospective-target block determines the strategic idea of the implementation of the model for the formation of CSPA in future OSH engineers, provides for the implementation of actions related to the determination of the main directions of research activities. In accordance with the goals, a set of basic research tasks was determined: development of the concept of formation of CSPA for future OSH engineers; substantiation of methodological approaches to the formation of the safety culture and mechanisms for their implementation; definition of basic and specific principles that determine the nature of creative interaction; creation of optimal psychological conditions for the creative development of students in higher education; definition of stages, types of organizational forms, methods, ways and means of development of students; development of a system of criteria and indicators to determine the level of formation of the main components of the model; identification of innovative technologies for the development of the creative potential of students; development of scientific and methodological support for the formation of CSPA.

The theoretical-methodological block reflects the substantiation of scientific concepts, approaches, principles and factors of the formation of CSPA in future OSH engineers. Scientific views, reflecting theoretical and methodological provisions, are set forth in the concept of the formation of CSPA in future OSH engineers. The theoretical and methodological basis for the formation of CSPA is systemic, humanistic, culturological, axiological, subject-subject, competence, activity. 


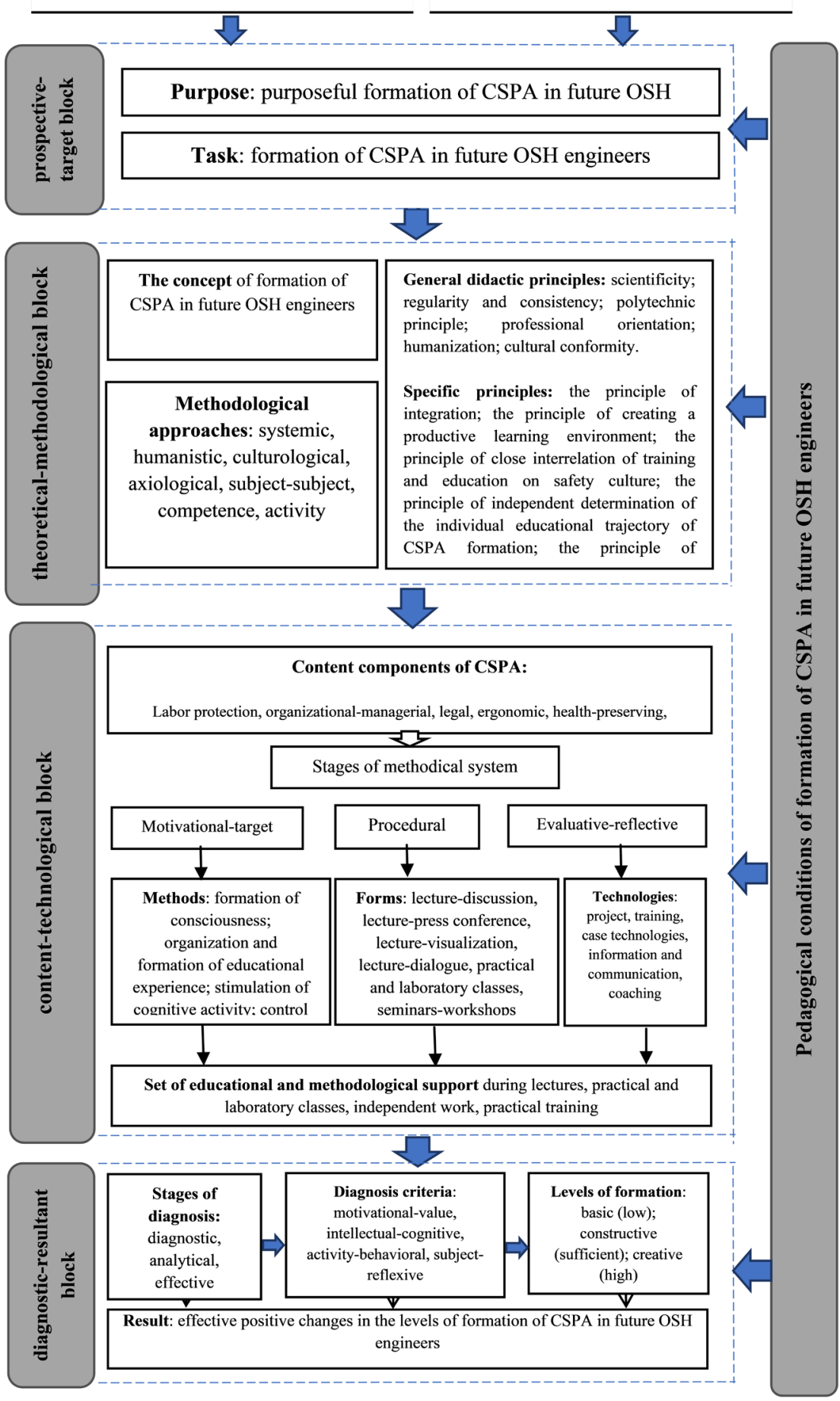

Fig. 1 Model of the formation of the safety culture of professional activity in future occupational safety and health engineers 
The implementation of the ideas of the personal and professional development of students in the process of CSPA formation is possible based on the following principles: general (scientific; systematic and consistent; polytechnic; principle of professional orientation; humanization; cultural conformity) and specific (the principle of taking into account the integration processes of higher education; principle of creation of a productive learning environment; the principle of a close interrelation between academic training and safety culture education; the principle of inclusion in innovative activities; the principle of self-determination of an individual educational trajectory for the formation of safety culture of professional activity; the principle of systematic organization of the process of CSPA formation; the principle of promoting a healthy lifestyle). The practical implementation of the model is predetermined by a certain group of pedagogical conditions that contribute to the effective formation of the CSPA in future OSH engineers. We referred to them: the formation of positive motivation for mastering CSPA; updating the content of vocational training for occupational safety and health engineers, taking into account the component of CSPA on the basis of interdisciplinary integration; the use of innovative technologies for the formation of CSPA in future OSH engineers; development of the creative readiness of future occupational safety and health engineers for safe activity.

The content-technological block of the model reflects the content and stages of the implementation of the methodological system for the CSPA formation in future OSH engineers. In accordance with the author's idea, the content of CSPA formation is represented by the following components: labor protection, providing the mastery by students of engineering and technical, sanitary and hygienic, information and analytical, monitoring knowledge and skills; organizational-managerial, involving the formation of students' knowledge and skills on the creation, functioning and improvement of the OSH management system at the enterprise, in institutions and organizations; legal, aimed at the formation of legal knowledge and practical skills in the application of legislative and regulatory requirements in the field of labor protection; ergonomic, contributing to a holistic understanding of the ergonomic features of the work process, methods and ways of creating comfortable and safe working conditions; health-preserving, including a system of biomedical knowledge about methods and means of preventing general and occupational diseases, ways to promote health; communicative, providing the development of communication skills and interpersonal interaction skills. The presented methodological system for the formation of CSPA in future occupational safety and health engineers is implemented in three stages: motivational-target, procedural, evaluative-reflective.

The motivational-target stage determines the activation of students' motivation to organize safe professional activity and preserve health.

The procedural stage involves the formation of students' relevant professional knowledge, skills and abilities in the field of labor protection, mastering the values of safety and norms of safe behavior, the development of professional and personal qualities, abilities for self-improvement, self-realization, and adequate self-assessment of their activities. The procedural stage is implemented at the first (bachelor's) level both in the process of studying professionally oriented disciplines in the field of labor protection, proposed by the educational and professional program, and by introducing specific disciplines that provide the content components of CSPA: «Labor protection management», «Legislative and legal basis of safety», «Workplace ergonomics», «Psychology of occupational safety», «Medical and biological foundations of safety», «Business communications», «Safety pedagogy». At the second (Master's) level, mastering knowledge on safety culture is carried out through the introduction of a special course «Safety culture of professional activity», as well as through the organization of self-educational activities to improve safety culture. 
The third evaluative-reflexive stage of the methodological system for CSPA formation in future OSH engineers makes it possible to check the effectiveness of the implementation of the developed model and determine the levels of formation of CSPA in the course of the educational process, as well as during industrial practices. In the process of implementing the tasks of the motivational-target and procedural stages of the formation of CSPA in future OSH engineers, the selected forms, methods, training technologies are important for our research. The methods contributing to the improvement of the cognitive activity of future OSH engineers for the formation of their CSPA include: methods of formation of consciousness (presentation of educational material, explanations, conversation, discussion, debate, lecture); methods of organizing and forming the experience of educational activities (reproductive, heuristic, problem methods, dialogue methods, illustrations and demonstrations); methods of stimulating cognitive activity (game methods, competition, portfolio); methods of control (interrogation, test, control work, development of graphic, technical and technological documentation). Organizational forms that contribute to the formation of the safety culture are the following: lectures, practical and laboratory works involving teamwork (in small groups, pairs), conducting training sessions, debates, discussion of issues at round tables, workshops, scientific and theoretical conferences, workshops.

The diagnostic-resultant block of the model of the formation of CSPA in future OSH engineers provides for monitoring, diagnostics and correction of the levels of formation of CSPA in future OS engineers through their readiness and ability to carry out professional activities. The presented block of the model includes the implementation of the following stages: diagnostic, aimed at the selection and implementation of a set of diagnostic tools, techniques, test technologies to establish the levels of formation of CSPA; analytical, implying the definition of criteria and indicators for assessing the levels of formation of CSPA in future OSH engineers; effective, providing an opportunity to study the dynamics of the formation of CSPA through the levels of formation of professional knowledge, skills, personal and professional qualities of future OSH engineers, and, if necessary, to make changes to the continuous process of formation of CSPA in future OSH engineers. In the course of scientific research, we have developed the following criteria: motivational-value, intellectual-cognitive, activity-behavioral, subject-reflexive with the corresponding indicators.

Within each criterion and indicator, the levels of formation of CSPA are determined: basic (low); constructive (sufficient); creative (high). The result of the implementation of the proposed model is effective positive shifts in the levels of CSPA formation in future OSH engineers.

\section{Conclusion}

Thus, the process of the formation of CSPA in future occupational safety and health engineers is one of the factors of successful adaptation to professional activities within the framework of regulatory requirements for occupational safety. The model presented in the study determines the vector of development of the process of CSPA formation in future OSH engineers, demonstrates the interrelation and complementarity of the justified blocks, stages, pedagogical conditions and means of formation of CSPA. The developed system is at the same time balanced, diagnostic and dynamic; it ensures the formation of all structural components of the CSPA, and determines the interpretation of the main conceptual provisions of the study. 


\section{References}

1. Shtoff, V. (1966). Modeling and Philosophy Moscow: Nauka.

2. Bespalko, V.P. (1977). Fundamentals of the theory of pedagogical systems. Voronezh: Voronezh State University Press.

3. Zagvyazinsky, V.I., \& Atakhanov, R. (2005). Methodology and methods of psychological and pedagogical research. Moscow: Publishing Center "Academy".

4. Kraevsky, V.V. (1994). Methodology of pedagogical research. Samara: SamGPI.

5. Luzan, P.H., Sopivnyk, I.V., \& Vyhovska, S.V. (2016). Methodology and organization of scientific and pedagogical research. Kyiv: Compress.

6. Radkevych, V.A. (2011). Principles of modernization of vocational education. Problems of modern teacher training, 3 (3), 331-337.

7. Boziev, R.S., Pichugina, V.K., Serikov, V.V. (2016). Methodology of scientific research in pedagogy. Moscow: Planeta.

8. Khrykov, E.M. (2017). Methodology of pedagogical research. Kharkiv: Panov A.M.

9. Dronov, A.A. (2009). Formation of the life safety of students of secondary vocational education institutions. ( $\mathrm{PhD}$ thesis). Voronezh State Pedagogical University,Voronezh.

10. Shinkarenko, A.S. (2015). Pedagogical model of the formation of a safe and healthy lifestyle of schoolchildren. Bulletin of the Kemerovo State University, 1 (61), 132-137.

11. Usachev, N.A. (2010). Technology of formation of the culture of safety of professional activity among students of the faculties of physical culture. ( $\mathrm{PhD}$ thesis). National State University of Culture, Sports and Health named after P. F. Lesgaft, Saint-Petersburg.

12. Zubkov, M.E. (2012). The model of formation of the corporate culture of occupational safety. Social management, economics and law, 11, 96-100.

13. Tseiko, V.A. (2015). Life safety culture of high school students: essence, process of formation and results. Bulletin of the Bryansk State University, 1, 65-70.

14. Moshkin, V.N. (2004). Education of the safety culture for schoolchildren. (Doctoral dissertation). Barnaul State Pedagogical University, Barnaul.

15. Trofimets, E.N. (2010). Information and analytical technologies for training managers in educational institutions in Russia and abroad. Bulletin of the Russian University of Peoples ' Friendship, 1, 86-95.

16. Gorina, L.N., Kovaleva, A.A. (2010). Modeling of the human life safety system in the educational process. Proceedings of the Samara Scientific Center of the Russian Academy of Sciences, 5 (12), 35-39.

17. Dolinina, I.G., Kushnareva, O.V. (2015). Model of formation of the culture of life safety of students in the polytechnic university. Basic research, 9, 19-22.

18. Kazmina, A.V., \& Gaponenko, A.V. (2012). Formation of professional culture of bachelors in the field of environmental protection. Social Policy and Sociology, 5, 195203.

19. Alekseeva, S.V. (2018). Model of training future designers for professional career development. Art education: content, technology, management, 13, 16-26.

20. Zozulyak-Sluchik, G.V. (2019). Model of formation of professional ethics of future social workers in universities. Youth and Market, 6, 123-127.

21. Kulalaeva, N.V. (2019). Formation of the culture of safety of professional activity among future builders: theory and practice. Kyiv: Komprint.

22. Radkevych, A. (2020). Model of the pedagogical system for the development of legal culture of pedagogical workers in vocational education institutions. Professional Pedagogy, 2020, 1 (20), 56-63. https://jrnls.ivet.edu.ua/index.php/1/article/view/574 